\title{
Penile amputation and successful reattachment and the role of winter shunt in postoperative viability: A case report and literature review
}

\author{
Michael Fuoco, MD; ${ }^{*}$ Leonard Cox, $M D_{i^{\dagger}}$ Thomas Kinahan, $M D^{\S}$ \\ *Department of Urology, Queen's University, Kingston, ON; †Victoria General Hospital, Victoria, BC; §UBC/Kelowna General Hospital, Kelowna, BC
}

Cite as: Can Urol Assoc J 2015;9(5-6):E297-9. http://dx.doi.org/10.5489/cuaj.2522 Published online May 13, 2015.

\section{Abstract}

Traumatic self-amputation of the penis by a psychotic patient is rare. Microvascular replantation is the favored management approach. There are no known cases of self-amputation followed by ingestion of the stump and subsequent replantation. A 51-yearold patient with paranoid schizophrenia presented 2 hours following penile amputation. He had swallowed the excised portion, which was endoscopically retrieved from the stomach in the emergency department. Successful reattachment was achieved including microvascular repair of the dorsal penile arteries without cavernosal arterial anastamoses. A Winter's shunt was performed to improve venous circulation. The patient has been followed for 3 years from the date of repair. He has adequate erection for intercourse and good urinary function, but has experienced sensory loss over the dorsal aspect and glans and urethral stricture dilation. This is the first report of replantation following ingestion of an amputated penis.

\section{Introduction}

Traumatic amputation of the penis is a rare and alarming clinical presentation requiring urgent surgical intervention. Clinical cases may present in adults and children. In the former, typical scenarios include self-inflicted injury, felonious assault, or accidental trauma. ${ }^{1}$ In the case of self-inflicted penile amputation, acute psychosis is commonly associated. Greilsheimer and Groves found that in of the 53 cases of self-mutilation, 46 patients were psychotic. ${ }^{2}$

Ehrich performed the first penile replantation in $1929 .{ }^{3}$ Cohen and Tamai described the first microsurgical repair technique in 1977; it has been the preferred method of repair since, including venous and arterial anastomoses. ${ }^{4,5}$ Other methods have been used to manage arteries, veins, and nerves depending on the clinical scenario, including no vascular anastomoses, one artery, two arteries, and with or without venous anastomosis. ${ }^{6}$
Venous drainage following replantation is vital to the success of surgery and is achieved by anastomosing the dorsal veins of the penis. However, anastomosis of the dorsal veins is not always possible. In these instances, further interventions, such as leech therapy, have been utilized. ${ }^{7}$ One instance of spongiocavernosal shunt to aid in venous outflow has been described in the pediatric setting. ${ }^{8}$ Despite the importance of venous drainage, one case describes a successful macrosurgical reattachment without venous anastomoses. $^{9}$

Complications are common following replantation, and are well-described in a series of 18 penile amputations and replantations from an epidemic in Thailand in the 1970s, though most replantations were performed with non-microsurgical techniques. ${ }^{10}$ Complications include surgical site infections, skin necrosis, penile edema, urethral strictures, urethral fistula, and distal penile numbness. ${ }^{11,12}$ A microsurgical technique has been associated with lower rates of complications, specifically fistula formation, urethral stenosis, skin necrosis, loss of sensation, and erectile dysfunction. ${ }^{6,13}$ A number of cases using the microsurgical technique have shown good functional outcomes in long-term follow-up, including the presence of erections, ejaculation and sensation, as well as adequate length, and normal urine flow. ${ }^{12,14-16}$

We describe a case and follow-up of a self-inflicted penile amputation, ingestion of the amputated stump, and microvascular surgical replantation with Winter's shunt in a paranoid schizophrenic patient.

\section{Case report}

In January 2011, a 51-year-old paranoid schizophrenic with a self-inflicted penile amputation came to the emergency department in Kelowna, British Columbia. On arrival, the patient was questioned about this history which revealed that he had swallowed his amputated penis. Within roughly 1 hour of ingestion, the gastroenterology service performed an endoscopic retrieval of the penis from the patient's stomach. Careful examination of the amputated penis showed minimal gastric acid injury and a clean cut through the mid- 
Fuoco et al.

shaft of the penis. After consultation with the plastic surgery service, we decided to proceed with a penile replantation.

His deep dorsal vein, superficial dorsal vein, both superficial arteries and associated nerves were identified and suitable for repair. His urethra was repaired with an end-to-end anastamosis of the urethral serosa with 7-0 nylon sutures over a 20Fr Foley catheter (Fig. 1). Tunica albuginea was repaired circumferentially with interrupted 3-0 Vicryl sutures after it was determined that no corporal arteries were large enough for repair. Microvascular repair was then performed repairing the deep dorsal vein, superficial dorsal vein, and both superficial arteries and nerves with 9-0 and 10-0 nylon sutures. Despite full venous repair, a Winter's spongiocavernosal shunt was performed to maximize venous drainage (Fig. 2).

His Foley catheter was removed 4 weeks later and he initially voided well. He had some delayed wound healing on the ventral aspect of his penis, which resolved with time. He impressively reported having erections following repair, though he suffered from low libido secondary to antipsychotic medications. He initially had some distal penile numbness as well, which also slowly improved with time. Furthermore, he had a postoperative symptomatic urethral stricture that was treated with urethral dilation to $20 \mathrm{Fr}$.

\section{Discussion}

Penile amputation with successful microvascular replantation has been described. This, however, is the first report of replantation following ingestion of an amputated penis. The penis seemed to suffer minimal trauma from being in the stomach for at least an hour, and the fact that the replantation was successful shows that ingestion of an amputated penis is not a contraindication to replantation. Coordination

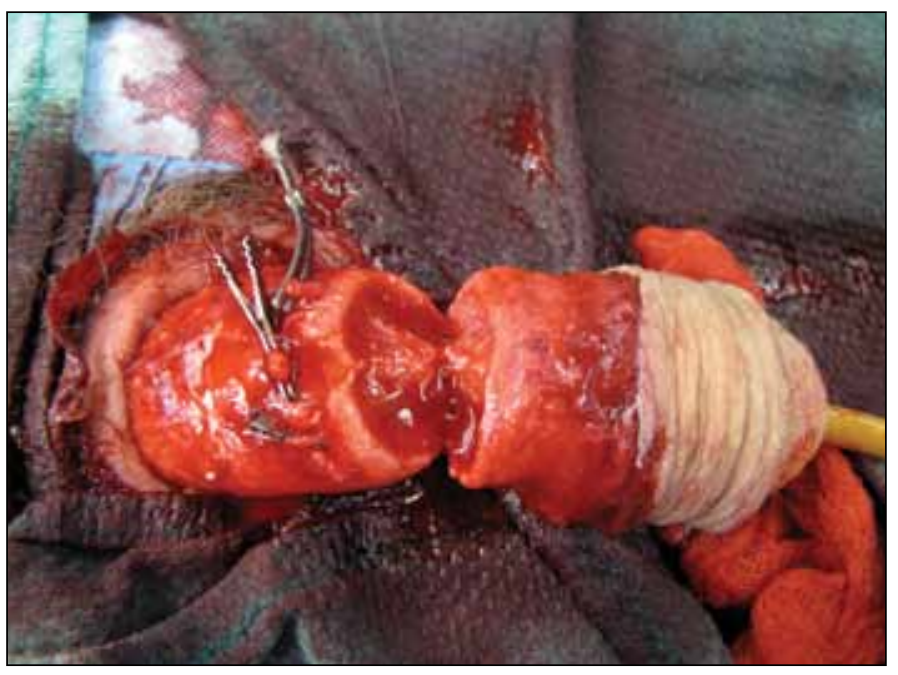

Fig. 1. Intraoperative view after urethral anastomosis. with the appropriate services, including gastroenterology and plastic surgery, clearly contributed to the surgery's success.

With respect to technical repair, both superficial dorsal arteries were repaired in this case and no cavernosal arteries were repaired because the cavernosal arteries were not large enough. Literature suggests that repair of at least one dorsal artery instead of cavernosal arteries alone improves penile replant viability, ${ }^{11}$ and our case further supports this claim. Performing dorsal arterial anastomoses appears to positively affect outcomes and thus should be performed whenever possible. Conversely, the absence of cavernosal arterial anastomoses did not negatively affect outcomes in this case, and so may not always be necessary.

Venous drainage is described as an integral part of a successful replantation of the penis. ${ }^{6}$ Spongiocavernosal shunts have been described in cases in which venous repair was not feasible, ${ }^{8}$ though it is performed rarely. There are no cases describing the combination of microvascular venous repair in addition to spongiocavernosal shunting. As such, the benefits of shunting following microvascular replantation are not clearly defined, but this case suggests it may aid in avoiding complications associated with venous congestion of the replanted penis. The Winter's (spongiocavernosal) shunt was performed with an 18-gauge core needle biopsy, which is slightly smaller than the typically used 14-gauge Tru-cut needle. Nonetheless, a successful outcome was observed so the larger needle bore may have been unnecessary in this scenario.

Follow-up of this patient showed some minor complications, including delayed wound healing, distal penile numbness, and urethral stricture. These are all commonly described in the literature. ${ }^{1,6,10}$ Retaining erectile function after a complete amputation of the penis has also been

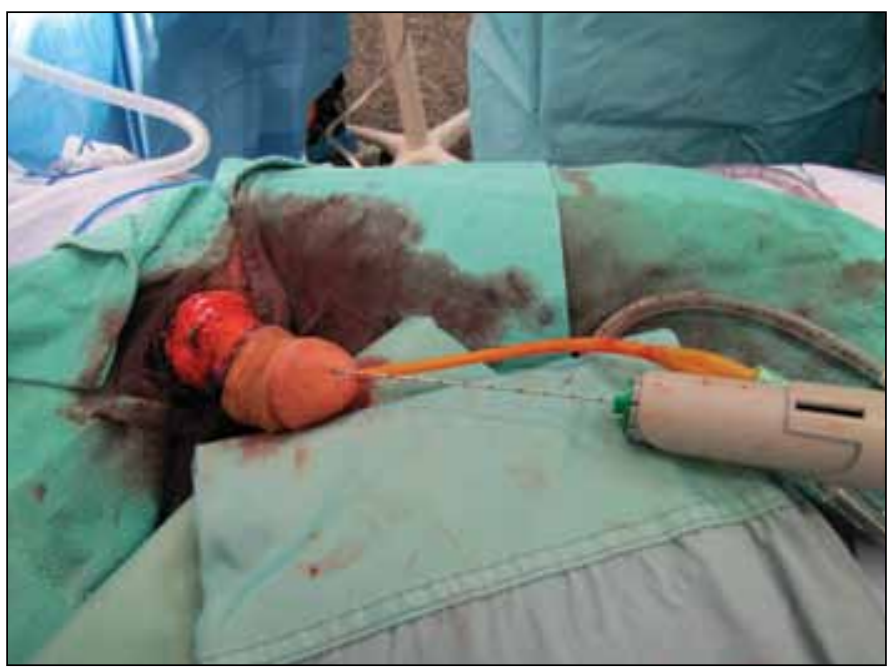

Fig. 2. Winter's (spongiocavernosal) shunt being performed. 


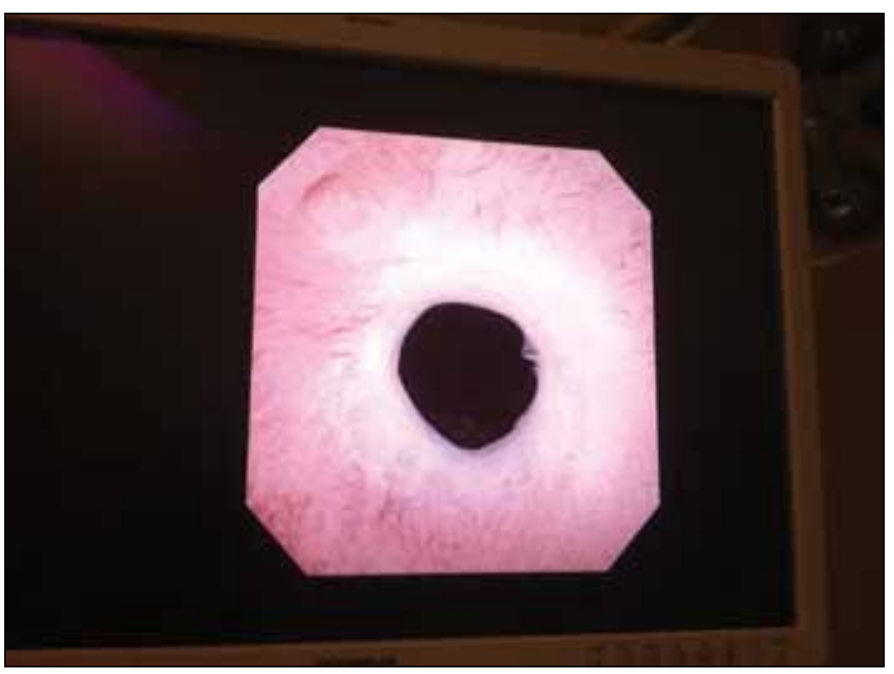

Fig. 3a. Cystoscopic view of postoperative urethral stricture.

described. ${ }^{12,14-16}$ However, the minimal complications and the maintenance of erectile function are particularly impressive in this case given that the amputated penis was ingested prior to replantation.

\section{Conclusion}

This is the first report of replantation following ingestion of an amputated penis. Successful replantation was performed without cavernosal arterial anastomoses. A Winter's shunt may have improved venous drainage following replantation. Complications were minimal, and the patient had good voiding and erectile function postoperatively.

Competing interests: The authors declare no competing financial or personal interests.

This paper has been peer-reviewed.

\section{References}

1. Jezior JH, Brady JD, Schlossberg SM. Management of penile amputation injuries. World J. Surg 2001;25:1602-9. http://dx.doi.org/10.1007/s00268-001-0157-6

2. Greilsheimer H, Groves JE. Male genital self-mutilation. Arch Gen Psychiatry 1979;36:441-6. http:// dx.doi.org/10.1001/archpsyc. 1979.01780040083009

3. Ehrich WS. Two unusual penile injuries. J Urol 1929;21:239.

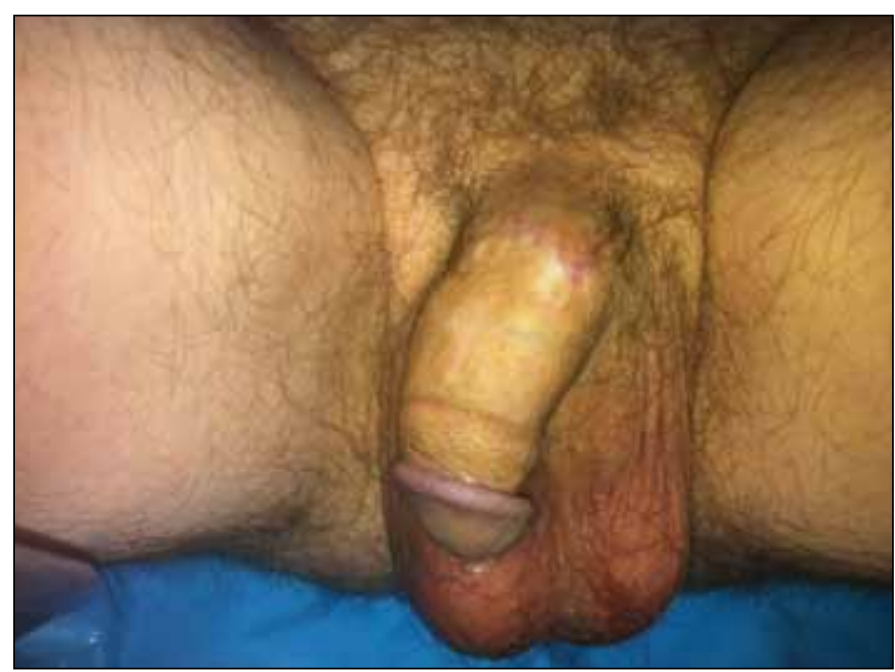

Fig. 3b. Postoperative appearance following successful replantation.

4. Cohen BE, May JW, Daly JSF. Successful clinical replantation of an amputated penis by microneurovascular repair. Plast Reconstr Surg 1977;59:276-80. http://dx.doi.org/10.1097/00006534-19775902000023

5. Tamai S, Nakamura Y, Motomiya Y. Microsurgical replantation of a completely amputated penis and scrotum. Plat Reconstr Surg 1977;60:287-91. http://dx.doi.org/10.1097/00006534-19770800000028

6. Babaei A, Safarinejad M. Penile replantation, science or myth? A systematic review. Urol J 2007;4:62-5.

7. Pantuck AJ, Lobis MR, Cioca R. Penile replantation using the Leech Hirudo Medicinalis. Urology 1996;48:953-6. http://dx.doi.org/10.1016/S0090-4295(96)00318-4

8. Ozkan $S$, Gurpinar T. A serious circumcision complication: Penile shaft amputation and a new reattachment technique with a successful outcome. J Urol 1997;158:1946-7. http://dx.doi.org/10.1016/ S0022-5347(01)64187-9

9. Riyach 0, El Maidoub A, Tazi MF. Succesful replantation of an amputated penis: A case report and review of the literature. J Med Case Rep 2014;8:125. http://dx.doi.org/10.1186/1752-1947-8-125

10. Bhanganada K, Chayavatana T, Pongnumkul C. Surgical management of an epidemic of penile amputations in Siam. Am J Surg 1983;146:376-82. http://dx.doi.org/10.1016/0002-9610(83)90420-8

11. Landstrom JT, Schuyler RW, Macris GP. Microsurgical penile replantation facilitated by postoperative HBO treatment. Microsurgery 2004;24:49-55. http://dx.doi.org/10.1002/micr.10192

12. Naraynsingh $V$, Harnarayan $P$, Hariharan S. Successful penile replantation using loupe magnification. Int Urol Nephrol 2011;43:437-9.

13. Li GZ, Man LB, He F. Replantation of amputated penis in Chinese men: A meta-analysis. Zhong Hua Nan Ke Xue 2013;19:722-6.

14. Lidman $D$, Danielsson $P$, Abdiu A. The functional results two years after a microsurgical penile replantation. Scand J Plast Reconstr Hand Surg 1999;33:325-8. http://dx.doi.org/10.1080/02844319950159325

15. Sanger JR, Matloub HS, Yousif NJ. Penile replantation after self-inflicted amputation. Ann Plast Surg 1992;29:579-84. http://dx.doi.org/10.1097/00000637-199212000-00017

16. Salem HK, Mostafa T. Primary anastomosis of the traumatically amputated penis. Andrologia 2009;41:2647. http://dx.doi.org/10.1111/i.1439-0272.2009.00925.x

Correspondence: Dr. Michael Fuoco, Department of Urology, Queen's University, Kingston, ON; mfuoco@qmed.ca 